\title{
DEMOCRACIA E DIVERSIDADE CULTURAL
}

\author{
Paulo Serra \& Bruno Serra
}

\begin{abstract}
RESUMO
Com o dito latino Hic rhodus hic saltus, referido no prefácio da sua Filosofia do Direito, pretendia Hegel sublinhar que cabe à filosofia estudar o que é, o real, e não o que deveria ser. Nos anos 60 do século XX, o real era, para os estudos culturais ingleses, a revolução cultural em curso desde os finais da II Guerra Mundial, e que tornava crucial o estudo de questões como as da relação entre cultura e poder, cultura popular e cultura de massa, homogeneidade cultural e diversidade cultural. As reflexões dos autores dos estudos culturais, ingleses e outros, em relação a estas questões, continuam hoje a ser cruciais e, diríamos mesmo, mais cruciais do que nunca. Partindo do trabalho levado a cabo pelos estudos culturais no domínio da cultura, o presente artigo reflete sobre as condições de uma democracia que respeite a pluralidade e a diferença das culturas, não só a nível do estado nacional, hoje em profunda mudança, mas também a nível mundial/global. De forma algo anacrónica, deixamos Hegel e a sua ancoragem ao real para regressarmos a Kant e ao seu ideal de uma sociedade cosmopolita.
\end{abstract}

\section{Palavras-Chave}

Estudos culturais; diversidade cultural; democracia; participação; globalização

\begin{abstract}
Through the Latin saying Hic rhodus hic saltus, mentioned in the preface of his Philosophy of Right, Hegel intended to emphasise that it is Philosophy's duty to study what is real, rather than what ought to be. During the $60^{\prime}$ 's of the $20^{\text {th }}$ century, what was real was, as far as British Cultural Studies were concerned, the cultural revolution ongoing since the end of the II World War, which made critical the study of such issues as the relationship between culture and power, popular culture and mass culture, cultural homogeneity and cultural diversity. The considerations on these issues produced by cultural studies' authors - British and otherwise - remain crucial today, perhaps more so than ever. Setting the work carried through by cultural studies in the domain of culture, this paper aims to reflect upon the condition of a democracy that respects plurality and cultural differences, not only at national state level - presently undergoing deep changes - but also at a global level. In order to do so, we will somewhat anachronistically move beyond Hegel and his tethering to the real by returning to Kant and his ideal for a cosmopolitan society.
\end{abstract}

\section{KEYWORDS}

Cultural studies; cultural diversity; democracy; participation; globalization 


\section{INTRODUÇÃo}

A reflexão presente neste texto tem como ponto de partida o trabalho dos estudos culturais inaugurados pelo Centre for Contemporary Cultural Studies (CCCS), da Universidade de Birmingham, fundado em 1964 por Richard Hoggart, que foi também o seu primeiro diretor, e dirigido depois, a partir de 1969, por Stuart Hall.

Estes estudos culturais contribuíram, de forma decisiva, para a viragem cultural [cultural turn] que teve lugar na segunda metade do século $X X$, e que pode ser vista como um prolongamento da viragem linguística que ocorreu nos princípios desse mesmo século (Chaney, 1994, pp. 1-2; Hall, 2007). O principal efeito e sinal de tal viragem é a "centralidade da cultura", traduzida em aspetos como o desenvolvimento das indústrias da cultura, a importância crescente da cultura nos vários aspetos da vida social e económica, os efeitos da cultura nos diversos discursos e disciplinas, a afirmação da cultura como categoria central de análise da vida social contemporânea (Hall, 2007, p. 39).

Nesse sentido, os estudos culturais ingleses acabam por constituir, também, uma das principais fontes daquilo a que hoje se chama os "estudos de cultura", que têm um âmbito mais vasto que os primeiros e que não envolvem, necessariamente, um comprometimento político de esquerda ou outro.

No entanto, nem sempre é fácil delimitar o que se entende propriamente por "estudos culturais". Assim, referindo-se aos Estados Unidos, dizia Hall (1990, p. 22) que a designação cultural studies se tinha tornado "um chapéu para quase tudo". De facto, aquilo a que se chama os "estudos culturais" sempre comportou uma grande multiplicidade e diversidade de objetos e disciplinas, com raízes nas humanidades e nas ciências sociais, e que impedem reduzi-los a uma escola, a de Birmingham ou outra qualquer (Hall, 1992).

Apesar da sua filiação no marxismo - ou, pelo menos, numa certa versão gramsciana do marxismo, centrada na noção de "hegemonia" - os estudos culturais distinguem-se da ortodoxia marxista pelo menos em dois aspetos fundamentais: i) não reduzem as sociedades contemporâneas à distinção entre burguesia e proletariado, considerando que elas são muito mais diversas do que isso do ponto de vista cultural, envolvendo diferenças de género, de raça, de etnia, de idade, etc.; ii) dão uma atenção central aos media, não assumindo sobre eles, no entanto, a posição apocalíptica da escola de Frankfurt (Adorno e Horkheimer), aproximando-se mais de posições como as de Walter Benjamin ou Hans Erzensberger.

Esta sua atenção à diversidade cultural e aos media como elementos centrais das sociedades contemporâneas faz com que os estudos culturais sejam um ponto de partida obrigatório para pensarmos as questões da democracia e da cidadania nestes tempos que são os nossos - no sentido de tematizarmos aquilo a que, adiante, chamamos uma democracia plural e radical e uma cidadania global.

\section{A Crítica da CUltura de Frankfurt a Birmingham}

Quando se fala dos estudos culturais e da sua análise crítica das sociedades contemporâneas, é praticamente impossível - e mesmo injusto - não se referir a escola de Frankfurt. 
De facto, apesar das cerca de quatro décadas que separam a criação do Institut für Sozialforschung da Universidade de Frankfurt (em 1923, por Felix Weil) e a do Centre for Contemporary Cultural Studies da Universidade de Birmingham (em 1964, por Richard Hoggart), ambos partilham vários pontos em comum (Kellner, 1997): a sua filiação marxista; a sua recusa de uma versão primária do marxismo, assente na distinção entre infraestrutura e superstrutura e na suposta determinação da segunda pela primeira; o relevo dado ao tema da cultura, que ultrapassa a distinção infraestrutura/superstrutura; a sua visão crítica daquilo a que Adorno e Horkheimer (1944/2002) chamam a "indústria da cultura" [Kulturindustrie] e Hoggart (1957/2009) chama a "cultura de massa"[mass culture].

No entanto, há também importantes diferenças entre ambas as correntes, em particular as duas seguintes: a resistência à cultura de massa provém, para a escola de Frankfurt, da "alta cultura", enquanto para os estudos culturais ela provém da cultura popular, em particular da classe trabalhadora; para a escola de Frankfurt a resistência à cultura de massa é praticamente impossível, já que a produção determina totalmente a receção, enquanto para os estudos culturais a resistência existe em muitos casos, na medida em que a receção pode ser feita quer no sentido pretendido da produção, quer em sentido diverso, quer mesmo em sentido oposto - aquilo a que Stuart Hall (1973/1980) chama a posição dominante-hegemónica, a posição negociada e a posição oposicional.

A crítica da escola de Frankfurt à indústria da cultura assenta, de facto, em dois pressupostos básicos: a distinção entre alta e baixa cultura; a identificação da cultura produzida pela indústria da cultura com a baixa cultura.

Ora, ambos os pressupostos são problemáticos.

Quanto à distinção entre alta e baixa cultura, ela esquece que uma cultura nacional ou grupal é um todo heterogéneo, que engloba elementos tanto de "alta cultura" - as artes, a filosofia, a ciência - como de "baixa cultura", incluindo-se aqui a cultura popular, no sentido da cultura predominantemente oral, herdada das gerações anteriores por uma espécie de osmose, e a própria cultura de massa, a cultura veiculada pelos meios de comunicação de massa, em geral com caráter transnacional. Este mesmo entendimento da cultura como um todo heterogéneo é partilhado pela Unesco (2002, Preambule), para quem

a cultura deve ser considerada como o conjunto de traços distintivos, espirituais e materiais, intelectuais e afetivos, que caraterizam uma sociedade ou um grupo social e engloba, para além das artes e das letras, os modos de vida, as maneiras de viver em conjunto, os sistemas de valores, as tradições e as crenças.

Estes vários traços coexistem em cada cultura de forma mais ou menos harmoniosa, comunicando entre si quer por uma língua comum, quer por aquilo a que Luhmann chama os meios de comunicação simbolicamente generalizados, e em que se incluem o dinheiro, o poder, a influência, os compromissos de valor, a verdade, ou o amor (Luhmann, 1981). Assim, expressões como "alta cultura" ou "baixa cultura" não passam de meras abstrações, assentes em juízos de valor que, numa sociedade ou grupo social, 
determinados estratos sociais emitem em relação a outros e à respetiva cultura, visando, em última análise, legitimar a sua hegemonia - mesmo quando os extratos emitentes são, alegadamente, "intelectuais humanistas" ou "intelectuais de esquerda".

Quanto à identificação da cultura produzida pela indústria da cultura com a baixa cultura, ela esquece que, por um lado, muita da "alta cultura" se transforma em cultura "industrial" - por exemplo a arte de Picasso ou de Andy Warhol - e que, por outro lado, muita da cultura "industrial" é, verdadeiramente, "alta cultura" - por exemplo os filmes de Charlie Chaplin ou Orson Welles. Na realidade, a expressão "indústria da cultura" designa mais um processo de produção e de difusão da cultura - a cultura como informação na era industrial - do que propriamente o seu conteúdo.

Os estudos culturais são, precisamente, um sintoma daquilo a que, parafraseando Arthur Danto e o seu "fim da arte" (Danto, 1984), poderíamos chamar o fim da (alta) cultura como aura e distinção, e que leva a que a cultura passe a ser vista como uma realidade "ordinária" (Williams, 1958/1989). Em ambos os casos, o que está em causa é a descrença num cânone, num critério normativo que define universalmente o que é valioso e o que não o é, para passar a critérios empíricos, de base sociológica e antropológica e, portanto, particulares.

Esse fim da alta cultura como cânone leva a uma espécie de negacionismo por parte dos defensores da "alta cultura", de que um dos exemplos mais recentes e conhecidos é o de Vargas Llosa, que vê na hodierna "cultura do espetáculo" (ou entretenimento) exemplificada em produtos como as telenovelas brasileiras, os filmes de Hollywood ou os shows de Shakira - a morte da verdadeira cultura, que visava durar e eternizar-se, e não ser consumida e esquecida no momento (Vargas Llosa, 2013). Mais comedido, algumas décadas antes de Vargas Llosa, já Steiner (1971) tinha teorizado o advento de uma pós-cultura. Ora, não deixa de ser curioso este apego de muitos dos intelectuais "humanistas" do Ocidente à chamada "alta cultura" - já que se ela não criou, pelo menos não evitou as duas guerras mundiais que tiveram lugar no século $X X$, bem como toda a barbárie que as acompanhou, não sendo raros os casos de algozes dos campos de concentração que gostavam de enviar os presos para a morte ao som de música erudita...

Se no tempo em que reinava a (ideia de) alta cultura, os espaços privilegiados da mesma eram os museus, as bibliotecas e as universidades, hoje a cultura é vista como sendo de todos os lugares, incluindo aqueles, mas também todos os outros: a fábrica (a cultura operária), a cozinha (a cultura gastronómica), o estádio (a cultura desportiva), etc.

Tal não implica, no entanto, que no seio de uma cultura tudo seja considerado como igualmente importante. Definir o que é e o que não é importante, ou o que é mais ou menos importante aponta, desde logo, para a questão da relação entre cultura e poder.

\section{Cultura E PODER: DA VIRAgEM CULTURAL À VIRAgem POPUlista}

A questão da relação entre cultura e poder está presente, logo desde o seu início, nos estudos culturais ingleses. Assim, Raymond Williams, em The long revolution - um dos três textos que, a par de Uses of literacy, de Richard Hoggart e Making of the English 
working class, de E. P. Thompson, Stuart Hall (1980) considera seminais nesta corrente -, afirma a necessidade de pensar em conjunto, como um mesmo processo, a revolução industrial, a revolução democrática e a revolução cultural, de forma a dar-se conta da "longa revolução" em curso (Williams, 1961/1963 pp. 9-15). O texto de Stuart Hall mencionado sublinha, por seu lado, a ligação da linha de pensamento dos três autores/ livros com a agenda da Nova Esquerda [New Left], que colocava a "política do trabalho intelectual" no centro da nova corrente (Hall, 1980, p. 58).

Também membros das gerações mais recentes dos estudos culturais sublinham esta preocupação de pensar a relação entre cultura e poder, particularmente as relações de poder que determinam quem é representado e quem o não é, quem fala e quem é silenciado, mesmo o que conta como "cultura" (Couldry, 2000, p. 2). Relativamente a tais relações de poder, os valores afirmados pelos estudos culturais "são os da democracia cultural e política e da eliminação progressiva das desigualdades de poder" (Couldry, 2000, p. 6). Quanto ao tipo de democracia que aqui está em causa, o mesmo autor cita o seguinte extrato de The long revolution: "se o homem é, essencialmente, um ser que aprende, cria e comunica, a única organização social adequada à sua natureza é uma democracia participativa na qual todos nós, enquanto indivíduos únicos, aprendemos, comunicamos e controlamos" (Williams citado em Couldry, 2000, p. 26).

Em texto mais recente, Couldry (2006) apontava como características dos estudos culturais não apenas a ênfase no consumo da cultura e na cultura popular, mas, sobretudo, a preocupação com as profundas desigualdades na forma como os sujeitos podem tomar a palavra, "emergir como sujeitos falantes" (p. 26). De modo análogo, ao referir-se a Raymond Williams, Storey (2017) refere que o objeto dos estudos culturais é a cultura e o poder, entendendo-se a cultura como um conjunto de significados simultaneamente partilhados e contestados; quanto ao poder, o mesmo autor sublinha a influência do conceito de hegemonia de Gramsci nos estudos culturais e na sua distanciação do marxismo clássico e da ideia da determinação da infraestrutura, considerando-se todo o resto - nomeadamente o género - como "meramente cultural" (Butler, 1997).

A partir da década de oitenta do século $X X$, os estudos culturais vão sofrer um duplo processo de internacionalização e de institucionalização. A primeira, que terá provocado impactos sobre os estudos culturais nem sempre positivos (Grossberg, 1993), leva a que eles passem a estar presentes nas academias de todo o mundo (Miller, 2001), incluindo Portugal (Baptista, 2009; Martins, 2010; Sampaio, 2013) e Brasil (Escosteguy, 2010). A segunda refere-se, precisamente, à entrada dos estudos culturais na academia, dando a origem a cursos de graduação e pós-graduação, a projetos de investigação, etc., em parte como resposta à crise das humanidades (Hall, 1990).

Mas este (aparente) sucesso dos estudos culturais terá sido, simultaneamente, causa e consequência de uma "viragem populista" [populist turn], que leva a um "populismo cultural" que acaba por considerar o capitalismo como "cool" (McGuigan, 2011).

Os estudos culturais transformam-se, assim, em meros estudos de receção, caindo na "conformidade cultural" (Miller \& Philo, 2000), celebrando o "popular" e as "audiências ativas" (Miller \& Philo, 2001), esquecendo os momentos - e os poderes - da 
produção e da circulação da cultura e estabelecendo a "grande divisão" entre análise da cultura e economia política (Murdock, 1995; para uma visão crítica mais alargada deste processo, ver Ferguson \& Golding, 1997).

O alegado poder das audiências no momento da receção faz esquecer que essa receção está, logo à partida, condicionada pelo que é dado a receber, pelo seu enquadramento, pelos canais em que é veiculado, pelo seu custo, etc. - por aquilo a que, no seu conjunto, se pode chamar as condições de produção, circulação e reprodução da cultura. Dito de outra forma: situar os estudos cultuais apenas no momento da receção ou consumo implica aceitar e legitimar, de forma implícita, tudo o que está antes desse momento, isto é, o essencial da "indústria da cultura" (Adorno \& Horkheimer, 1944/2002) e da "cultura de massa" (Hoggart, 1957/2009).

No entanto, talvez possamos falar, a este respeito, de uma terceira viragem, a viragem reflexiva - para dar conta de que a crítica da "viragem populista", empreendida quer dentro, quer fora do campo dos estudos culturais criou as condições para a superação desse populismo. O trabalho de críticos como McGuigan (2011), Couldry (2000, 2006, 2010) ou Storey (2017), para nos referirmos apenas a alguns exemplos, que voltaram a colocar na agenda dos estudos culturais a relação entre cultura e poder comprova, precisamente, essa viragem reflexiva. Os estudos culturais regressam, deste modo, à inspiração fundamental dos seus "fundadores", ainda que os objetos concretos em análise possam ser outros, como a Web, as redes sociais, a globalização, etc.

\section{A DEMOCRACIA DE MASSAS E O PROBleMA DA PARTICIPAÇÃo}

A afirmação de que os Gregos inventaram a democracia é verdadeira, mas incompleta: de facto, os Gregos inventaram um certo tipo de democracia - a democracia participativa -, muito diferente daquilo que os Modernos designarão por tal nome.

Quanto à sua forma, a democracia carateriza-se por dois princípios fundamentais: a igualdade de todos os cidadãos perante a lei e o respeito pela vontade da maioria na tomada de decisões. Mas estes princípios definem, precisamente, isso: a forma da democracia, não o seu conteúdo ou substância. Os Gregos juntaram, a ambos os princípios, o princípio da participação: participação não só nos debates públicos e nas tomadas de decisão políticas, mas também nos diversos órgãos de governo da cidade, de tal modo que cada cidadão era, ao mesmo tempo, governado e governante.

Sabemos que um tal tipo de democracia participativa coloca problemas de espaço (que não pode ser muito grande), de tempo (que não pode ser muito longo) e de número (dos cidadãos envolvidos, que não pode ser muito elevado). Ao estabelecer a identidade entre o homem e o cidadão, a democracia moderna vem tornar críticos os problemas do espaço, do tempo e do número. Para resolver esses problemas, e contra a perspetiva de filósofos como Rousseau, os Modernos fizeram assentar a sua democracia num princípio diverso do da participação: o da representação e da delegação do poder.

Deste modo, o processo de inclusão de todos os homens, que distingue a democracia moderna em relação à grega, só foi possível abdicando do princípio da participação e 
colocando, no seu lugar, o princípio da representação - reduzindo-se a participação dos representados, no essencial, à escolha dos seus representantes.

Ora, na representação, cada um dos cidadãos é tratado de forma abstrata, como um ente numérico, um x igual a um outro x. A suposta "vontade geral" não resulta, assim, da coordenação dos interesses particulares e das diferenças dos cidadãos, mas antes da anulação - da colocação entre parêntesis - desses interesses e diferenças. $\mathrm{Na}$ democracia representativa, ser um cidadão quer dizer: anular-se como cidadão. A representação envolve, desta maneira, um verdadeiro paradoxo: só se representa alguém na condição de não o representar enquanto alguém em concreto, mas enquanto abstração.

Os únicos que escapam a esta lógica da anulação são os eleitos - e eleitos no duplo sentido do termo: as elites políticas que são, simultaneamente, as elites económicas e culturais, nalguns casos mesmo as velhas elites de sangue (aristocratas).

No entanto, e reciprocamente ao que acontece com os representados, também os representantes - os eleitos - se caraterizam por um número, o do seu peso (eleitoral), traduzido em número de votos.

Estes problemas da representação, que levam a uma transmutação da política em mera estatística (eleitoral), tornam-se ainda mais agudos com a transformação da "sociedade (ou comunidade) de públicos" em "sociedade de massas" (Mills, 1956/2000, pp. 300-301).

Esta transformação, que terá começado em meados do século XIX, tem na sua base fatores como "a industrialização, a urbanização, o crescimento da literacia e da imprensa popular e, não menos importante, a emergência do estado administrativo e intervencionista" (Dahlgren, 1991, p. 4). A estes fatores devem ser adicionados, até pela importância crescente que irão assumindo, os meios de comunicação de massa (Dahlgren, 1991, p. 1).

Teremos, assim, massas em todos os domínios das sociedade: nas cidades - massas de indivíduos reservados, habitando um espaço caracterizado pelo anonimato, a impessoalidade e a indiferença perante as coisas e as pessoas (veja-se o ensaio de Georg Simmel sobre a metrópole e a vida mental, datado de 1903); na produção - massas de trabalhadores acoplados às máquinas nas linhas de produção, facilmente substituíveis uns pelos outros (o sistema taylorista, tal como retratado em Os tempos modernos, de Charlie Chaplin, estreado em 1936); no consumo - massas de consumidores a que se destinam os objetos produzidos em série (o Ford T, de Henry Ford, lançado em 1908); na cultura - leitores, ouvintes ou espectadores que fruem os mesmos produtos culturais, produzidos de modo mais ou menos uniforme (o sistema de produção do cinema de Hollywood a partir do anos 20 do século XX, por exemplo); massas, enfim, na política - configurando aquilo a que se tem vindo a chamar a "democracia de massa" (Mills 1956/2000, p. 307; Stoker, 2006).

Se o advento da "sociedade de massas" é encarado, por autores como Gustave Le Bon (1895) ou Ortega y Gasset (1929) como o início da dominação da cena política pelas massas, e a consequente perda de poder das elites, não é essa, no entanto, a opinião de Wright Mills, que aqui perfilhamos. 
De facto, enquanto na democracia liberal dos séculos XVIII e XIX ainda prevalece uma certa proximidade entre os representantes e os representados, que criam as suas associações voluntárias, e prevalece a ideia de que a política deve ser um debate racional e crítico sobre o comum, a democracia de massas vem aprofundar a distância entre os representantes e os representados, colocando entre eles partidos e outras organizações de massa que funcionam de forma mais ou menos autotélica e em que as elites conversam com as elites, substituindo o debate entre cidadãos pela manipulação e pela propaganda, usando para isso os mass media. Estes não são, assim, apenas um dos fatores da emergência da sociedade de massas, são também um dos principais meios de que as elites económicas e políticas se servem para exercer o seu poder sobre as massas (Mills, 1956/2000, p. 315).

O que falta à democracia assente no princípio da representação para ser de facto democracia é, como dissemos atrás, o princípio da participação. É ao participar nos vários círculos em que decorre a sua vida social que cada um dos cidadãos pode "representar-se" a si próprio, fazer valer os seus interesses e diferenças.

Não que o princípio da representação tenha de ser anulado - a questão é, antes, a de saber como é que, numa democracia de massas, ambos os princípios podem ser articulados - e isto a todos os níveis em que os processos de decisão política têm lugar, desde o local de trabalho até ao parlamento nacional ou mesmo supranacional.

Esta era, podemos dizer, a fundamental exigência teórica e prática - militante, política e pedagógica - dos estudos culturais ingleses nas suas origens: como tornar a democracia de massas mais democrática? Como radicalizar a democracia? Como vimos, a "longa revolução" referida por Raymond Williams pressupunha que a "revolução democrática" fosse acompanhada, para além de uma "revolução industrial", de uma "revolução cultural", ou seja, que a economia, a política e a cultura fossem vistas em conjunto. Este é, justamente, o tema da secção que se segue.

\section{UMA DEMOCRACIA RADICAL E PLURAL}

Uma democracia que não seja meramente formal - isto é, que não reduza a participação cidadã ao voto - implica o respeito prático e jurídico-político pelas diferenças entre indivíduos e grupos e pela diversidade cultural'. Mas as diferenças que aqui estão em jogo são as especificamente culturais, ou seja, aquelas que os indivíduos ou grupos mobilizam discursivamente para se distinguirem de outros indivíduos ou grupos e, desse modo, definirem a sua própria identidade (Appadurai, 1996, pp. 12-13).

Como já referimos, uma das direções fundamentais dos estudos culturais ingleses foi a sua atenção às diferenças culturais - diferenças de género, de raça, de etnia, de idade, etc. -, indo neste aspeto muito para além das diferenças de classe já apontadas pelo marxismo mais ortodoxo.

' Apesar de os dicionários os considerarem praticamente como sinónimos, tomamos aqui os termos diferença e diversidade em sentidos distintos. Assim, enquanto a diferença é o que permite distinguir um indivíduo ou grupo de um outro indivíduo ou grupo, a diversidade refere-se ao facto de haver indivíduos e grupos diferentes. Ela será tanto maior quanto maior for o número de indivíduos ou grupos diferentes e quanto maiores forem as diferenças entre indivíduos ou grupos. 
Esta posição dos estudos culturais sobre a importância da diversidade cultural, que era também já a de Lévi-Strauss (1952/1987, especialmente pp. 13-17), foi recentemente (re)afirmada pela Unesco (2002), numa declaração que considera a diversidade cultural tão importante para o género humano como a biodiversidade para a ordem dos seres vivos, e que vê como seu limite apenas os direitos do homem (esta era também, no essencial, a posição defendida por Lévi-Strauss).

Em contraste com esta posição, subsiste ainda hoje a posição daqueles que, defendendo a ideia de uma cultura - a que por vezes chamam "humanista" - defendem que a diversidade não é senão uma forma de valorizar aquilo que não é, de facto cultura, mas um seu sucedâneo. Esta posição, a que já atrás nos referimos, decorre também de uma postura etnocêntrica que valoriza o que é judaico-cristão, grego e europeu - e, dirão muitas filósofas, masculino - em detrimento do que o não é, e que é só a maior parte do mundo (nem culturas tão antigas e importantes como as da China e da Índia fazem parte desse mapa mental eurocêntrico dos "humanistas").

A diversidade é uma questão política básica porque a sua afirmação ou negação equivalem a reconhecer a todos ou a recusar a alguns o direito à visibilidade e à participação na vida social. Não há diversidade se o que é diverso não aparece aos olhos de todos, no espaço público (Arendt, 1958).

Uma democracia que procura respeitar as diferenças e a diversidade cultural pressupõe uma política a que autores como Ernesto Laclau e Chantal Mouffe (1985/2001) chamam uma "política democrática radical".

Esta "política democrática radical" é caraterizada pelos autores como um projeto que pretende unir as velhas lutas dos trabalhadores com as novas lutas das minorias (as mulheres, os jovens, os homossexuais, os negros, etc.) e a redistribuição económica com o reconhecimento social - estendendo as exigências de democracia, de liberdade e igualdade, do domínio da economia e do trabalho aos domínios do género, da raça, da etnia, etc. Ainda de acordo com Laclau e Mouffe, esta democracia é radical porque cada uma das identidades coletivas vale por si mesma; e é plural porque considera as diferentes identidades em presença como igualmente importantes. No entanto, ela não implica renunciar à democracia deliberativa, mas antes estender o seu impulso democratizante, libertário e igualitário em direção a uma democracia que pode assumir diversas formas de participação e exercício, consoante os coletivos e os espaços de que se trata.

Neste mesmo sentido, Grossberg (2015) refere a necessidade de articulação, à esquerda, entre uma "política vertical", e uma "política horizontal", uma democracia deliberativa/representativa e uma democracia participativa - se bem que, tal como no caso de Laclau e Mouffe, permaneça em aberto a questão crucial de saber como estabelecer, na prática, essa articulação.

Se a democracia tem a ver com a inclusão do diferente, a cidadania tem a ver com a participação na democracia (Storey, 2017), podendo-se mesmo falar de uma "cultura" de cidadania (Couldry, 2006).

Impõe-se, portanto, uma cidadania cultural que, a par da cidadania política ("direito a residir e votar") e da cidadania económica ("direito a crescer e prosperar"), insista "num direito à comunicação e à representação da diferença cultural" (Miller, 2011, p. 57). 
Adotando uma distinção de Giroux (2000), é imprescindível uma "cultura da política" [culture of politics] que leve os cidadãos a participar na vida cívica e política, e que é indissociável de uma "política da cultura" [politics of culture], que tem de ser aprendida, fomentada e aprofundada. Daí a importância de uma pedagogia dos estudos culturais que seja não apenas política, mas também insurgente (Giroux, 2001).

Insurgente quer dizer: que não se limite a desviar os olhos ou mesmo a fazer a apologia do neoliberalismo atual - que, no fundo, não é mais do que um darwinismo social elementar.

Segundo Couldry (2010), uma política "pós-liberal", que conteste o neoliberalismo vigente, deve assentar na ideia de que todas as vozes devem ser ouvidas, que todas elas devem ter visibilidade no espaço social. Ora, as novas tecnologias da comunicação vieram trazer novas possibilidades para fazer ouvir essas vozes, já que permitem: a audição de novas vozes; a consciência mútua destas novas vozes; novas escalas de organização dos coletivos; outros espaços (não-espaços) de intervenção; novas intensidades do ouvir (pp. 139-141). Importa perguntar, no entanto, qual o real impacto destas novas vozes no sistema democrático: serão ouvidas apenas numa lógica de protesto e de contra democracia? É possível a sua articulação com as vozes institucionalizadas? Estas são questões decisivas, na medida em que "o déficit fundamental nas democracias é (...) não de voz, mas de valorização da voz, de envolvimento da voz nos processos de cooperação social" (Couldry, 2010, p. 144).

Uma nova política exige novos tipo de ação. Um deles, enunciado por Couldry, é o ato de saudação [greeting], por exemplo "deixando os trabalhadores migrantes assistir, falar e ter as suas perspetivas levadas em conta numa reunião do conselho municipal". De um modo mais geral, acrescenta Couldry, "os atos de saudação questionam as formas de invisibilidade que excluem as pessoas da gama de possíveis atores políticos" (Couldry, 2010, p. 146).

Esta questão da aceitação do Outro ganha uma importância cada vez maior num mundo em que os fluxos migratórios e culturais se tornaram a verdadeira regra.

\section{UMA CIDADANIA GLOBAL}

O pensamento político clássico sobre a democracia refere-se, de forma mais ou menos explícita, a uma democracia que existe no contexto de um estado-nação; a própria ideia clássica de cidadania tem como pressuposto esse mesmo estado-nação.

Ora, nestes tempos que vivemos, uma política democrática "pós-liberal" implica estender a democracia em duas direções diferentes e complementares: para cá do nacional, para o regional e o local, incluindo aqui a autarquia local, a escola, o local de trabalho, etc.; e para lá do nacional, para o transnacional e o global.

A necessidade de estender a questão da democracia ao nível global, e de colocar a questão da possibilidade de uma "cidadania global", decorre das próprias características da globalização, nomeadamente as que se referem ao domínio cultural.

Como sublinha a conhecida definição de Giddens (1990, p. 64), a globalização pode ser definida como "a intensificação de relações sociais mundiais que unem localidades 
distantes de tal modo que os acontecimentos locais são condicionados por eventos que acontecem a muitas milhas de distância e vice-versa". Tendo em conta esta definição, a globalização implica um conjunto de fluxos que ultrapassam e apagam todas as fronteiras, e que, não sendo exclusivos dos tempos mais recentes, neles ganharam toda a sua amplitude: fluxos de pessoas (migrantes, estudantes, turistas, refugiados...), de comunicações (as rádios, as tvs por cabo e por satélite, a internet...), de dinheiro e outros produtos financeiros (ações, etc.) e de mercadorias, incluindo aqui os chamados bens culturais (livros, filmes, discos...). O sistema aberto e reticular da globalização, que tem o seu símbolo maior na internet, contrasta, assim, com o sistema fechado e linear da guerra fria, cujo símbolo maior era o Muro de Berlim, derrubado em 1989 (Friedman, 1999).

No conjunto dos fluxos referidos, e no que se refere especificamente à globalização cultural, o antropólogo Arjun Appadurai destaca o efeito interligado das comunicações eletrónicas - e, em particular, das imagens que estas veiculam - e das migrações, que aponta para um espaço que, mais do que deslocalizado, integra muitos espaços simbólicos diferentes (Appadurai, 1996, pp. 2-4). E Appadurai dá os seguintes exemplos do funcionamento integrado de ambos os processos:

quando os trabalhadores Turcos na Alemanha veem filmes turcos nos seus apartamentos alemães, os Coreanos de Filadélfia veem as Olimpíadas de 1988 em Seul através de emissões satélites da Coreia, e em Chicago os taxistas paquistaneses ouvem cassetes de sermões gravados em mesquitas no Paquistão ou no Irão, vemos imagens em movimento que vão ao encontro de espectadores desterritorializados. Estes criam esferas públicas de diáspora, fenómenos que confundem as teorias que dependem do relevo continuado do Estado-nação como árbitro principal de importantes transformações sociais. (Appadurai, 1996, p. 4)

Appadurai filia esta sua perspetiva no trabalho de Benedict Anderson sobre as "comunidades imaginadas": tal como as comunicações de massa escritas, nomeadamente os jornais e as novelas, fizeram emergir o estado-nação, também, defende Appadurai, as comunicações eletrónicas estão a fazer emergir um mundo pós-nacional, globalizado (Appadurai, 1996, p. 8).

As "esferas públicas da diáspora" mencionadas por Appadurai colocam vários desafios, a vários níveis políticos, todos de difícil solução.

Um primeiro desafio, a nível de cada um dos estados nacionais que acolhem os migrantes, é o da integração destes, conciliando a sua igualdade jurídico-política com a sua diferença cultural, o "modelo jacobino" com o "modelo multicultural" (Gignac, 1997) - não propriamente condescendendo com as diferenças culturais, mas reconhecendo essas diferenças e promovendo o envolvimento dos "diferentes" na atividade cívica e política (sobre o) comum (Taylor, 1992/1994). A atual situação em vários países da Europa e nos EUA - o auto intitulado "ocidente humanista" -, caraterizada por derivas nacionalistas, xenófobas e racistas de vários matizes mostra quão difícil é, na prática, aceitar o princípio da pluralidade e da diferença das culturas. 
Um segundo desafio, a nível da relação bilateral ou multilateral entre os estados nacionais, é o da circulação dos migrantes de um estado para outro, à procura de meIhores condições de vida. Como o mostraram, recentemente, a votação da maioria dos cidadãos ingleses a favor do Brexit, ou a abstrusa proposta do atual presidente dos EUA de construção de um muro entre os EUA e o México, a pagar por este último país, a circulação de migrantes encontra-se sempre ameaçada por novos muros, simbólicos e reais.

Um terceiro desafio, a nível global ou quase-global, é o da concretização do ideal utópico de organizações como as Nações Unidas ou a União Europeia, de construção de uma cidadania supranacional, mundial ou europeia. No entanto, para além da sua falta de poder efetivo, estas organizações carecem de maior democracia e maior igualdade entre os países que as integram - sob pena de, numa lógica estritamente neoliberal, (continuar a) imperar a lei do mais forte a nível económico, político e/ou militar.

Todos e cada um destes desafios fazem-nos, mais uma vez, tomar consciência de que, tal como escreve Grossberg (2017) em título de artigo dedicado à crise atual (estadunidense), "não há garantias na história". Ou seja: perdida para sempre a crença na redenção histórica prometida pela Fé, pela Razão ou pelo Partido, nada pode substituir a ação de cada um de nós - uma ação sempre frágil e contingente, mas que, juntamente com todas as outras ações igualmente frágeis e contingentes, é a única forma de irmos traçando rumos no tempo.

O que nos leva a regressar, na secção final deste texto, ao carácter político e crítico dos estudos culturais, para questionar o lugar dos intelectuais que hoje os investigam, ensinam e discutem um pouco por todo o mundo.

\section{CONSIDERAÇÕES FINAIS}

Fosse ou não para salvar as humanidades em crise, os estudos culturais fizeram a sua entrada na academia: nos centros de investigação, nos cursos de graduação e pós-graduação, nas disciplinas. Multiplicaram os seus objetos de estudo, diversificaram-se, ocuparam os interstícios dos saberes e das práticas. Em muitos casos, de críticos e contestatários, ter-se-ão tornado respeitados e respeitosos - institucionalizaram-se, deixaram de ser "políticos".

Pode-se observar, em relação a esta situação de facto, que não compete ao intelectual ser "político" no sentido de propor uma política concreta, apesar de não haver uma distinção clara e simples entre o trabalho intelectual e o trabalho político (Grossberg, 2010, pp. 242-243).

De facto, o trabalho intelectual nunca deixa de ser político. Regressamos aqui, mais uma vez, a Marx e à sua XI tese sobre Feuerbach: "os filósofos apenas interpretaram o mundo de diferentes maneiras; o que importa é transformá-lo" (Marx, 1845/2007, p. 536).

Mesmo que aceitemos que interpretar o mundo é diferente de o transformar - o que é muito discutível, dado que toda a interpretação transforma, desde logo, quer o próprio intérprete, quer a coisa interpretada -, o que é certo é que há determinadas interpretações que nos levam a ver o mundo de uma outra forma, às vezes radicalmente 
diferente, e que nos incitam mesmo a transformá-lo - tal como aconteceu, precisamente, com a interpretação da história feita pelo próprio Marx; e que, pelo contrário, há outras interpretações que nos levam a aceitar o estado vigente do mundo, a deixar tudo tal como está.

Em termos concretos, parece ser forçoso reconhecer-se que o trabalho intelectual de autores como Richard Hoggart, Raymond Williams, Edward P. Thompson ou Stuart Hall, em Inglaterra, ou de Roland Barthes, Michel Foucault ou Pierre Bourdieu, em França, para darmos apenas alguns exemplos, é político desde os seus começos: nos temas que escolhem, na forma como os tratam, nas consequências que extraem do seu tratamento ${ }^{2}$.

O trabalho intelectual destes autores não teve apenas efeitos teóricos, a nível de um saber que se aprende, se discute, se contesta ou se aceita - e isso já seria muito; teve, também, efeitos práticos, levando muitos jovens e menos jovens, trabalhadores ou estudantes, militantes ou nem por isso, a associar-se, a tomar posições, a desenvolver ações de rua, etc.; neste aspeto, e como dissemos, o caso de Foucault é paradigmático.

Portanto, o trabalho intelectual é sempre político - pode é ser político de diferentes maneiras: pode apoiar o status quo, pode contrariar esse status quo, ou pode pura e simplesmente abster-se de tomar posição - o que não deixa de ser uma posição como outra qualquer.

No caso concreto dos estudos culturais, eles têm na sua génese a crítica do poder em nome da cultura e da democracia. "Fazer estudos culturais" no sentido real da expressão implica, necessariamente, adotar uma tal postura crítica e política.

Se e quando tal não acontece, é porque não se trata, de facto, de estudos culturais; tratar-se-á, certamente, de uma outra coisa: a profissão, a carreira, mesmo algo tão passageiro como uma tese ou uma dissertação.

\section{REFERÊNCIAS BIBLIOGRÁFICAS}

Adorno, T. \& Horkheimer, M. (1944/2002). The culture industry: Enlightenment as mass deception. In G. S. Noerr (Ed.), Dialectic of Enlightenment: Philosophical Fragments (pp. 94-136). Stanford: Stanford University Press.

Appadurai, A. (1996). Modernity at large: Cultural dimensions of globalization. Minneapolis, Londres: University of Minnesota Press.

Arendt, H. (1958). The human condition. Chicago: The University of Chicago Press.

Baptista, M. M. (2009). Estudos culturais: o quê e o como da investigação. Carnets, Cultures littéraires: nouvelles performances et développement, 451-461. Retirado de http://carnets.web.ua.pt/

Butler, J. (1997). Merely cultural. Social Text, 52/53, 15(3-4), 265-277.

Chaney, D. (1994). The cultural turn: Scene-setting essays on contemporary cultural history. Londres: Routledge.

\footnotetext{
${ }^{2}$ Em relação ao caso específico - e exemplar - de Foucault, veja-se o documentário de François Caillat, Foucault contre lui-même, França, 2014, 52 minutos. Versão legendada em português disponível em https://www.youtube.com/ watch? $\mathrm{v}=\mathrm{FVKw} 8 \mathrm{~V}-\mathrm{CgXk}$
} 
Couldry, N. (2000). Inside culture: Re-imagining the method of cultural studies. Londres, Thousand Oaks, Nova Delhi: Sage Publications.

Couldry, N. (2006). Culture and citizenship: The missing link? European Journal of Cultural Studies, 9(3), $321-339$.

Couldry, N. (2010). Why voice matters: Culture and politics after neoliberalism. Londres, Thousand Oaks, Nova Delhi: Sage Publications.

Dahlgren, P. (1991). Introduction. In P. Dahlgren, \& C. Sparks (Eds.), Communication and citizenship: Journalism and the public sphere in the new media age (pp. 1-23). Londres: Routledge.

Danto, A. C. (1984). The end of art. In B. Lang (Ed.), The death of art (pp. 5-35). Nova lorque: Haven Publications.

Escosteguy, A. C. (2010). Cartografias dos estudos culturais: Uma versão latino-americana. Belo Horizonte: Autêntica.

Ferguson, M. \& Golding, P. (Eds.) (1997). Cultural studies in question. Londres: Sage.

Friedman, T. L. (1999). Duelling globalizations: a debate between Thomas L. Friedman and Ignacio Ramonet. Foreign Policy, 116, 110-127.

Giddens, A. (1990). The consequences of modernity. Cambridge: Polity Press.

Gignac, J.-L. (1997). Sur le multiculturalisme et la politique de la différence identitaire: Taylor, Walzer, Kymlicka. Politique et Sociétés, 16, 31-65. doi: 10.7202/040066ar

Giroux, H. A. (2000). Cultural studies and the culture of politics: beyond polemics and cynicism. jac 20(3), 505-540.

Giroux, H. A. (2001). Cultural studies as performative politics. Cultural Studies - Critical Methodologies, 1(1), $5-23$.

Grossberg, L. (1993). Cultural studies and/in new worlds. Critical Studies in Mass Communication, 10(1), 1-22. doi: $10.1080 / 15295039309366846$.

Grossberg, L. (2010). On the political responsibilities of cultural studies. Inter-Asia Cultural Studies, 11(2), 241247. doi: $10.1080 / 14649371003616375$.

Grossberg, L. (2015). We all want to change the world. Londres: Lawrence \& Wishart. Retirado de https://www. Iwbooks.co.uk/sites/default/files/free-book/we_all_want_to_change_the_world.pdf

Grossberg, L. (2017). There are no guarantees in history: A cultural studies perspective on the current crisis. Truthout. Retirado de https://tinyurl.com/zzbq2cg

Hall, S. (1973/1980). Encoding/decoding. In S. Hall; D. Hobson; A. Lowe \& P. Willis (Eds.), Culture, media, language (pp. 128-38). Londres: Hutchinson.

Hall, S. (1980). Cultural studies: Two paradigms. Media, Culture and Society, 2(1), 57-72.

Hall, S. (1992). Cultural studies and its theoretical legacies. In L. Grossberg, C. Nelson, \& P. A. Treichler (Eds.), Cultural Studies (pp. 277-294). Nova lorque, Londres: Routledge.

Hall, S. (2007). Richard Hoggart, The Uses of Literacy and the cultural turn. International Journal of Cultural Studies, 10(1), 39-49. doi: 10.1177/1367877907073899 
Hoggart, R (1957/2009). The uses of literacy. Londres: Penguin.

Kellner ${ }_{\text {S }}$ D. (1997). The Frankfurt School and British Cultural Studies: The missed articulation. In J. McGuigan (Ed.), Cultural methodologies (pp. 12-41). Londres, Thousand Oaks, Nova Delhi: Sage Publications.

Laclau, E., \& Mouffe, C. (1985/2001). Hegemony and socialist strategy: Towards a radical democratic politics. Londres: Verso.

Le Bon, G. (1895). Psychologie des foules. Paris: Félix Alcan.

Lévi-Strauss, C. (1952/1987). Race et histoire. Paris: Denoel.

Luhmann, N. (1981). The improbability of communication. International Social Science Journal, 23(1), 122-132.

Martins, M. L. (2010). Os Cultural Studies no Instituto de Ciências Sociais da Universidade do Minho. In M. L. Martins (Ed.), Caminhos nas Ciências Sociais: memória, mudança social e razão - Estudos em homenagem a Manuel da Silva Costa (pp. 271-287). Coimbra: Grácio Editor.

Marx, K. (1845/2007). 1. Ad Feuerbach (1845). In K. Marx \& F. Engels, A ideologia alemã: crítica da mais recente filosofia alemã em seus representantes Feuerbach, B. Bauer e Stirner, e do socialismo alemão em seus diferentes profetas (1845-1846) (pp. 533-535). São Paulo: Boitempo.

McGuigan, J. (2011). From cultural populism to cool capitalism. Art Q $Q$ the Public Sphere, 1(1), 7-18. doi: 10.1386/aps.1.1.7_1

Miller, D., \& Philo, G. (2000). Cultural compliance and critical media studies. Media, Culture Q Society, 22, 831-839. doi: 10.1177/016344300022006007

Miller, D., \& Philo, G. (2001). The active audience and wrong turns in media studies: Rescuing media power. Soundscapes, 4. Retirado de http://www.icce.rug.nl/ soundscapes/VOLUMEo4/Active_audience.shtml

Miller, T. (2001). Introduction. In T. Miller (Ed.), A companion to cultural studies (pp. 1-20). Malden, EUA / Oxford: Blackwell Publishers.

Miller, T. (2011). Cultural citizenship. MATRIZes, 4(2), 57-74.

Mills, C. W. (1956/2000). The power elite. Oxford: Oxford University Press.

Murdock, G. (1995). Across the great divide: Cultural analysis and the condition of democracy. Critical Studies in Mass Communication, 12(1), 89-95. doi: 10.1080/15295039509366922

Ortega y Gasset, J. (1929). La rebelión de las masas. Madrid: Revista de Occidente.

Sampaio, S. (2013). Portuguese cultural studies / Cultural studies in Portugal. Culture Unbound, 5, 73-88. Retirado de http://www.cultureunbound.ep.liu.se

Steiner, G. (1971). In a post-culture. In In Bluebeard's Castle: Some notes towards the redefinition of culture (pp. 59-93). New Haven: Yale University Press.

Stoker, G. (2006). Politics in mass democracies: destined to disappoint?. Representation, 42(3), 181-194. doi: $10.1080 / 00344890600844723$

Storey, J. (2017). The politics of culture. Middle East - Topics Q Arguments, 7, 15-21.

Taylor, C. (1992/1994). The Politics of Recognition. In A. Gutmann (Ed.), Multiculturalism and the politics of recognition (pp. 25-73). Princeton: Princeton University Press. 
Unesco (2002). Déclaration Universelle de l'Unesco sur la diversité culturelle. Adoptée par la $31^{\mathrm{e}}$ Session de la Conférence Générale de I 'Unesco, Paris, 2 Novembre 2001. Retirado de http://unesdoc.unesco.org/ images/0012/001271/12716om.pdf

Vargas Llosa, M. (2013). A civilização do espetáculo: uma radiografia do nosso tempo e da nossa cultura. Rio de Janeiro: Objetiva.

Williams, R. (1958/1989). Resources of hope: Culture, democracy, socialism. Londres, Nova Iorque: Verso.

Williams, R. (1961/1963). The long revolution. Londres: Penguin Books.

\section{NOTAS BIOGRÁFICAS}

Paulo Serra é Professor Catedrático na Universidade da Beira Interior (UBI), onde se doutorou em Ciências da Comunicação, em 2005. Atual presidente da Associação Portuguesa de Ciências da Comunicação (Sopcom), é investigador do LabCom.IFP da UBI. É autor dos livros A Informação como Utopia (1998), Informação e Sentido (2003) e Manual de Teoria da Comunicação (2008). É co-autor do livro Informação e Persuasão na Web (2009) e coorganizador de várias obras, a última das quais Politics and Web 2.o: The Participation Gap (2016).

E-mail: pserra@ubi.pt

Morada: Departamento de Comunicação e Artes, Universidade da Beira Interior, Rua Marquês D’Ávila e Bolama, 6201-001 Covilhã, Portugal

Bruno Serra é investigador do Centro de Ética, Política e Sociedade (CEPS), da Universidade do Minho, é licenciado em Filosofia e mestre no Ensino da Filosofia no Ensino Secundário pela UBI. Em 2016 obteve o Doutoramento em Filosofia pela Durham University (Reino Unido), resultante de uma Bolsa FCT. Publicações recentes incluem os capítulos Disposable Assets: Weyland-Yutani's Special Brew of Business Ethics (2017), Filosofia e Educação para a Cidadania (2015) e Citizenship and Political Action: the Dilemma between Patriotism and Cosmopolitanism (2015).

E-mail: bdserra@gmail.com

Morada: Centro de Ética, Política e Sociedade, ILCH - Universidade do Minho, Campus de Gualtar, 4710-057 Braga, Portugal

* Submetido: 15-05-2017

* Aceite: 15-07-2017 